\title{
Transdisciplinary and Transformative Research at the Intersection between Management, Healthcare, and Innovation
}

The vision of the Competence Center Health Network Engineering is to support the public and private stakeholders of healthcare by means of practical and forward-looking artifacts. Transdisciplinary research approaches, such as the innovative inclusion of very diverse individuals and groups of this domain, helps us to innovate our environment.

Transdisciplinary and Transformative Research at the Intersection between Management, Healthcare, and Innovation GAIA 23/3 (2014): 272-274 | Keywords: healthcare, innovation, management, trandisciplinarity, transformative research

\section{A Call for Transdisciplinary and Transformative Research for the Advancement of Healthcare}

Today, research in the area of management, healthcare, and innovation is focused on narrowly defined and very specialized problems. For instance, while public health researchers are interested in the effects of education on a population's health status (e.g., Lynch 2003), health economists examine behavioral changes due to policy implementation (e. g., Jilcott et al. 2007), and yet a health information scientist's attention is rather directed toward new technologies, such as electronic medical records, and its impact for doctors and health institutions (Black et al. 2011). Beyond all doubt, many benefits result from this specialization: cumulative, step-by-step research within a clearly defined discipline or "scientific community" has led to many accomplishments for modern society. It certainly also eased the work of scientists, since frequently a common set of knowledge, methods, and mind-set is shared. However, with the almost unlimited possibilities and freedom of modern society, also the challenges for national and international health systems increased. Today's problems are

Contact: Prof. Dr. Tobias Mettler | Tel.: +41 712243818 |

E-Mail: tobias.mettler@unisg.ch

Prof.Dr.Peter Rohner | E-Mail: peter.rohner@unisg.ch

Prof.Dr. Robert Winter | E-Mail: robert.winter@unisg.ch

all: University of St. Gallen (HSG) | Institute of Information Management (IWI) | Mueller-Friedberg-Str. 8 | 9000 St. Gallen | Switzerland

(C) 2014 T. Mettler et al.; licensee oekom verlag. This is an Open Access article distributed under the terms of the Creative Commons Attribution License (http://creativecommons.org/licenses/by/3.0), which permits unrestricted use, distribution, and reproduction in any medium, provided the original which permits unrestricte mostly complex, dynamic, and interwoven. Chronic diseases of epidemic scale, aging of population, surging costs, a lack of qualified health workers, and higher expectations of patients, local administrators or health insurers, are just a few of them. A singular perspective on such problems may not be suited to resolve the issue since crucial factors apparent only from other perspectives may be neglected. In this sense, it is not only important to foster relevant disciplinary research, but increasingly also transdisciplinary and transformative research.

\section{Vision of the Competence Center Health Network Engineering: Conducting Research with and for a Community of Practice}

Inspired by the transformative power of the Web and how - spontaneously or in more organized forms - networked individuals and institutions work together in order to achieve a common goal (Mettler and Rohner 2009), the Competence Center Health Network Engineering (CC HNE) was founded at the Institute of Information Management of the University of St. Gallen with the ambition to connect the diverse stakeholders of the healthcare sector, such as physicians, nurses, concerned citizens, managers and administrators, technology providers for the purpose of jointly solving relevant problems. Since its beginning, the CCHNE systematically makes use of the synergy harnessed from applied, transdisciplinary research in the intersection between management, healthcare, and innovation (see figure). A central element in our research has been innovative co-production of knowledge between these diverse disciplines as well as inclusion of "users" and their perspectives. In doing so, contextualization of our domain, for example, by means of characterizing stakeholders based on 
their actual needs instead of other superficial groupings (Mettler 2013) or by identifying and classifying context-specific solution and "use" patterns (Mettler and Eurich 2012, Rohner 2012), has been a cornerstone in our research. In this sense, all of our efforts are directed towards generating some kind of "utility" for society and the particular target groups in our triangle of research (i.e., healthcare, innovation, and management).

Another key focus has been on building a community of practice (Wenger 2000) consisting of a broad network of healthcare institutions, particularly hospitals, in order to foster a more vivid exchange of knowledge and best practices in and between single institutions and professional groups.

Each new project, such as our new Healthcare Connect idea (Rohner, Mettler, Winter 2014), ${ }^{1}$ extends this community and puts our research findings on a firmer base. A great part of any research project is therefore dedicated to support the overall vision of solving socially relevant problems by means of transdisciplinary knowledge creation and using this new evidence for transforming beliefs and behaviors of individuals and organizations.

\section{Artifacts as Boundary Objects for Bridging Social and Cultural Worlds}

Our research has always followed a pragmatic epistemology (Goldkuhl 2012). The essence of pragmatic research lies in the interplay between actions and change: In order to alter certain aspects of reality, actions are required. Knowledge (e. g., natural laws, social norms, empirical evidence) is essential to change reality into a desired end-state. Actions and their impact can also contribute to further cognitive clarification and development. This is in contrast to, for instance, descriptive research which primarily seeks to explain reality by using models (or a structure of relations) and which uses methods that emphasize the discovery of new knowledge and verify existing (structural) knowledge without deliberately distorting reality. It is also in the nature of pragmatic research to use a broad set of different research methods, including qualitative, quantitative and engineering methods.

Consequently, our work has favored methodological pluralism and multi-perspective examination of problems (Loos et al. 2013). Depending on the particular real-life problem, we used a widespread set of techniques in our diverse projects, including, for instance, focus group discussions with health professionals, observation, case studies, surveys, prototyping, and meta-analysis.

Major outcomes of our transdisciplinary research approach are artifacts. The term "artifact" is used to describe something that is artificial, or constructed by humans, in contrast to something that occurs naturally (Simon 1969). Such artifacts can take different forms such as conceptual blue prints, working software prototypes, instantiated processes and may be designed with the purpose of concrete (i.e., to solve a specific problem) and/or generic problem

1 Cf. http://ehealth.iwi.unisg.ch/healthcare-connect.

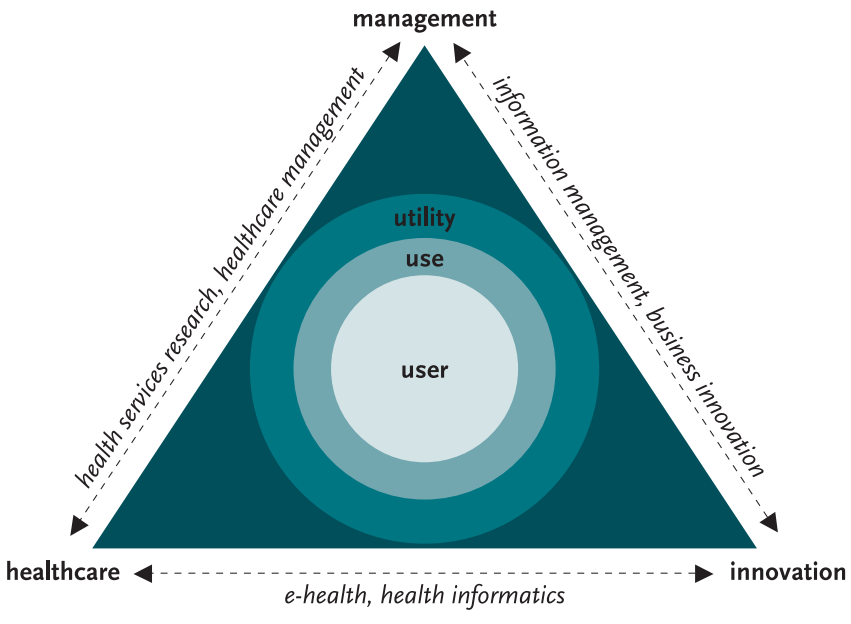

FIGURE: A community of practice as cornerstone for transformative and transdisciplinary research.

solving (i.e., to solve a class of problems). They are also designed for a specific user or user group, specific use scenarios, and with the aim to deliver some utility during its purposeful usage (Brenner et al. 2014). Another purpose of our artifacts is to serve as boundary objects; as bridges between social and cultural worlds (Nicolini et al. 2012). For instance, concatenating the "medical sphere", where the predominant rationale is to cure diseases, with the "private sphere", where rather well-being and leisure takes a central role. While it is somewhat hard to discuss abstract theories in a transdisciplinary setting, we found that it is easier to use artifacts as mediators between different communities of practice, respectively as common basis for conversations about problems and solutions (Dodgson et al. 2007).

\section{Tackling Large-scale, Societal Problems Requires New Research Approaches}

Society is facing ever more complex challenges, demanding fresh and unconventional approaches for understanding and solving them. We think that such large-scale problems need to be tackled conjointly and from different angles and viewpoints with the aim of extending the boundaries of human and organizational capabilities. Transdisciplinary and transformative research that puts the individual - respectively networks of individuals - and his or her situation-specific needs in the focal point of research is one way to anticipate one-sided - and thus often unusable or effectless - problem solutions.

Certainly, this kind of research is still in its fledgling stage. Many epistemological, methodological, as well as practical questions remain unanswered, which makes it particularly difficult for young researchers to follow this path. Without the strong support of our community of practice, it would have been impossible to gain such deep insights into the many challenges that individuals working at the intersection between management, healthcare, and innovation have to tackle every day. Hence, we believe that trans- 
disciplinary research approaches, such as the innovative inclusion of diverse stakeholders, is extremely valuable and allows us to develop more useful artifacts for society.

\section{References}

Black, A. D. et al. 2011. The impact of eHealth on the quality and safety of health care: A systematic overview. PLoS Medicine 8/1: e1000387. doi:10.1371/journal.pmed.1000387.

Brenner, W. et al. 2014. User, use \& utility research. Business \& Information Systems Engineering 6/1: 55-61.

Dodgson, M., D. M. Gann, A. Salter. 2007. "In case of fire, please use the elevator": Simulation technology and organization in fire engineering. Organization Science 18/5: 849-864.

Goldkuhl, G. 2012. Pragmatism vs interpretivism in qualitative information systems research. European Journal of Information Systems 21/2: 135-146.

Jilcott, S., A. Ammerman, J. Sommers, R. Glasgow. 2007. Applying the RE-AIM framework to assess the public health impact of policy change. Annals of Behavioral Medicine 34/2: 105-114.

Loos, P., T. Mettler, R. Winter, M. Goeken, U. Frank, A. Winter. 2013. Methodological pluralism in business and information systems engineering? Business \& Information Systems Engineering 5/6: 453-460.

Lynch, S. 2003. Cohort and life-course patterns in the relationship between education and health: A hierarchical approach. Demography 40/2: 309-331.

Mettler, T. 2013. Explorative clustering of clinical user profiles: A first step towards user-centered health information systems. Paper presented at the $27^{\text {st }}$ European Conference on Information Systems. Utrecht, The Netherlands, June 5-8.
Mettler, T., M. Eurich. 2012. A design pattern-based approach for analyzing e-health business models. Health Policy and Technology 2/1: 77-85.

Mettler, T., P. Rohner. 2009. An analysis of the factors influencing networkability in the health-care sector. Health Services Management Research 22/4: 163-169.

Nicolini, D., J. Mengis, J. Swan. 2012. Understanding the role of objects in cross-disciplinary collaboration. Organization Science 23/3: 612-629.

Rohner, P. 2012. Achieving impact with clinical process management in hospitals: An inspiring case. Business Process Management Journal 18/4: 600-624.

Simon, H. A. 1969. The sciences of the artificial. Cambridge, MA: MIT Press. Wenger, E. 2000. Communities of practice and social learning systems. Organization 7/2: 225-246.

Submitted May 26, 2014; revised version accepted July 9, 2014.

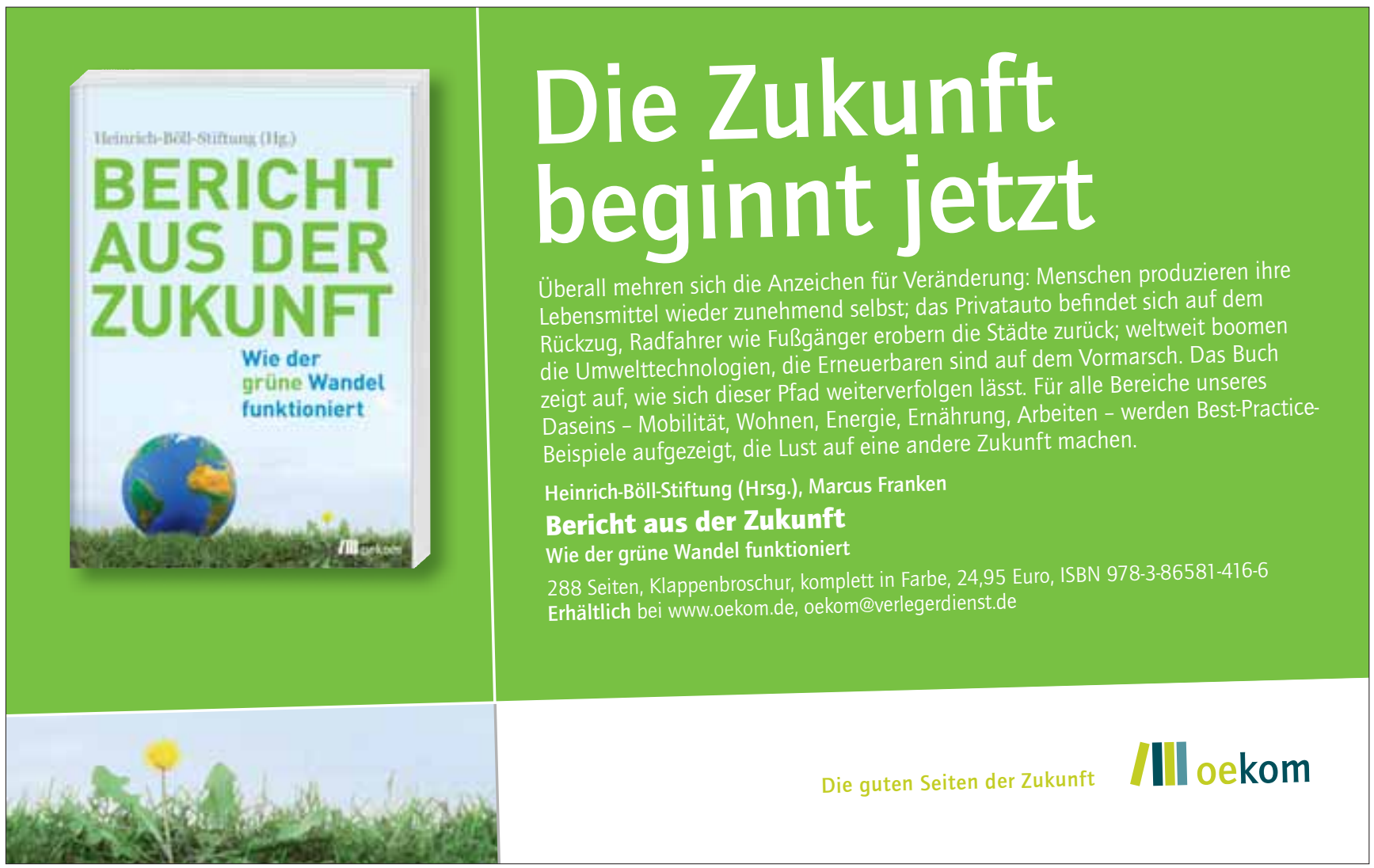

